\title{
Elucidation of the antistaphylococcal action of lactoferrin and lysozyme
}

\author{
E. C. LEITCH and M. D. P. WILLCOX \\ Cooperative Research Centre for Eye Research and Technology, University of New South Wales, 22-32 King \\ Street, Randwick 2031, NSW, Australia
}

\begin{abstract}
The cationic tear proteins lactoferrin and lysozyme exhibit co-operative antistaphylococcal properties. The purpose of this study was to determine the mechanism of action of this co-operation on Staphylococcus epidermidis. Following blocking of lipoteichoic acid (LTA) binding sites, the effects on binding of lactoferrin and susceptibility to lactoferrin and lysozyme were determined. The effect of lactoferrin on autolysis and LTA release was also examined. Maximal susceptibility occurred on addition of lactoferrin first followed by lysozyme. Blocking the LTA binding sites both reduced lactoferrin binding and decreased susceptibility. Autolytic activity decreased and LTA release increased in the presence of lactoferrin. These results suggest that binding of lactoferrin to LTA is important in its synergy with lysozyme and interferes with the autolysins present on the LTA. It is proposed that, on binding to the anionic LTA of $S$. epidermidis, the cationic protein lactoferrin decreases the negative charge, allowing greater accessibility of lysozyme to the underlying peptidoglycan.
\end{abstract}

\section{Introduction}

Individually, the cationic tear proteins lactoferrin and lysozyme display very different modes of antibacterial action. Lysozyme hydrolyses the $\beta$-glycosidic bonds of the repeating $\mathrm{N}$-acetylmuramic acid and $\mathrm{N}$-acetylglucosamine units that provide the rigidity of bacterial cell walls [1]. Most staphylococci are resistant to lysozyme [2]. A possible explanation for the lysozyme resistance of some gram-positive bacteria is the presence of anionic teichoic acids in the cell wall [3]. Lactoferrin, in its iron-limited form, displays an antimicrobial mechanism against a wide array of bacteria, including Staphylococcus epidermidis [4], which is unrelated to its iron-chelating ability [5]. The mode of action of lactoferrin on gram-positive bacteria is unknown. For gram-negative bacteria, lactoferrin causes the release of lipopolysaccharide (LPS) [6] leading to an increase in outer-membrane permeability [7].

In addition to their individual antibacterial mechanisms, lactoferrin and lysozyme exhibit co-operative antistaphylococcal properties for a range of $S$. epidermidis isolates which may contribute to the inability of this species to colonise contact lenses in vivo [8]. These

Received 11 Nov. 1998; accepted 24 Dec. 1998.

Corresponding author: Dr M. D. P. Willcox. proteins also act synergically against gram-negative bacteria, possibly due to permeabilisation of the outer membrane by lactoferrin allowing entry of lysozyme to the peptidoglycan [7]. Lactoferrin also enhances the action of various antimicrobial agents against gramnegative bacteria $[6,9]$ and $S$. epidermidis [10].

The purpose of this study was to analyse antistaphylococcal properties displayed by lactoferrin and lysozyme.

\section{Materials and methods \\ Sequential addition of lactoferrin and lysozyme}

The $S$. epidermidis isolate SE5 was used in this and all subsequent assays. Bacteria and artificial tear fluid containing serum (ATFS) were prepared as described previously [8]. Bacteria (1 in 10 dilution) were added to ATFS containing lactoferrin or hololactoferrin $(1.8 \mathrm{mg} / \mathrm{ml})$ and incubated for $6 \mathrm{~h}$ at $37^{\circ} \mathrm{C}$. Following addition of lysozyme $5.4 \mathrm{mg} / \mathrm{ml}$, the cultures were reincubated for a further $6 \mathrm{~h}$. Similarly, ATFS containing lysozyme was incubated for $6 \mathrm{~h}$, followed by addition of lactoferrin. Samples were taken at the beginning of the assay, after the addition of the second protein and at $7,8,10$ and $12 \mathrm{~h}$ from commencement of the assay. Viable counts were determined as described previously [8]. 
Viability following pre-incubation with antilipoteichoic acid

Anti-lipoteichoic acid was kindly supplied by Dr D. Harty of the Sydney Dental Hospital. Prepared bacteria were incubated with anti-lipoteichoic acid $(2 \%)$ raised in rabbits or rabbit serum $(2 \%)$ for $1 \mathrm{~h}$ at $37^{\circ} \mathrm{C}$ and added ( 1 in 10 dilution) to ATFS containing lactoferrin $1.8 \mathrm{mg} / \mathrm{ml}$. After incubation for a further $6 \mathrm{~h}$, lysozyme $5.4 \mathrm{mg} / \mathrm{ml}$ was added. Viable counts were performed as above on samples taken after $6 \mathrm{~h}$ and $12 \mathrm{~h}$ and compared with those determined in ATFS initially supplemented with lactoferrin only.

\section{Lactoferrin binding following pre-incubation with anti-lipoteichoic acid}

The ELISA developed previously [11] for the detection of lactoferrin binding to $S$. epidermidis isolates was modified. Plates containing absorbed SE5 cells were incubated with either anti-lipoteichoic acid, rabbit serum or buffer $(2,0.2$ or $0.02 \% \mathrm{v} / \mathrm{v})$ followed by the addition of iron-limited lactoferrin. The relative absorption of lactoferrin was determined as described previously. As controls, the binding of anti-lipoteichoic acid and serum (two-fold serial dilutions from $2.5 \%$ to $0.02 \% \mathrm{v} / \mathrm{v}$ ) to SE5 were also assayed as above, but without the addition of lactoferrin.

\section{Effect of lactoferrin on LTA release}

Biofilm-released cells were prepared as described previously [10] and pooled. Viable counts, determined as described previously, gave $c .1 \times 10^{8} \mathrm{cfu} / \mathrm{ml}$. These cells were then diluted (1 in 10) in TSB only or TSB containing lactoferrin $1 \mathrm{mg} / \mathrm{ml}$ and incubated for $4 \mathrm{~h}$ at $37^{\circ} \mathrm{C}$. Controls containing no bacteria were treated similarly. Cells were centrifuged at $2000 \mathrm{~g}$ at $4^{\circ} \mathrm{C}$ for $10 \mathrm{~min}$ and the supernate was filter-sterilised $(0.22-\mu \mathrm{m}$ pore size; Millipore). An ELISA was performed as above with anti-lipoteichoic acid (A) and the control rabbit serum (B) to detect the presence of lipoteichoic acid. The amount of lipoteichoic acid present was calculated by the following equation: $((A-B) / A) \times 100)$. Similarly, interference was detected by the controls and subtracted from the above calculation to give the percentage release of lipoteichoic acid.

\section{Effect of lactoferrin on autolytic activity}

Supernate from the above assay was used to detect autolysin activity as described previously [12]. Briefly, ammonium sulphate was added to $75 \%$ saturation and mixed for $1 \mathrm{~h}$ at $4^{\circ} \mathrm{C}$, then centrifuged at $12000 \mathrm{~g}$ for $30 \mathrm{~min}$ at $4^{\circ} \mathrm{C}$. The supernate was discarded and the pellet was resuspended in $0.1 \mathrm{M}$ sodium acetate buffer $(\mathrm{pH} \mathrm{6)}$ and dialysed against four changes of this buffer. Samples $(100 \mu \mathrm{l})$ in duplicate were added to 96-well plates and cell walls of Micrococcus lysodeikticus (Sigma), diluted to a concentration of $1 \mathrm{mg} / \mathrm{ml}$ in buffer, were added $(100 \mu \mathrm{l})$ to the wells. Following immediate determination of the $\mathrm{OD}_{570}$, the plate was incubated at ambient temperature and the $\mathrm{OD}_{570}$ was measured at 0.5 -h intervals for $2.5 \mathrm{~h}$.

\section{Statistical analyses}

Statistical analyses were performed by the Student's $t$ test for comparing growth in the presence of antilipoteichoic acid and MANOVA for all other analyses.

\section{Results \\ Viability following sequential addition of lactoferrin and lysozyme}

The results are shown in Fig. 1. Lactoferrin or lysozyme added after $6 \mathrm{~h}$ to cultures incubated in ATFS containing lysozyme or hololactoferrin, respectively, induced growth. This growth was significant $(p<0.001)$ compared with the loss in viability of the cultures initially grown in iron-limited lactoferrin with lysozyme added after $6 \mathrm{~h}$.

\section{Viability in ATFS following pre-incubation in anti-lipoteichoic acid}

Growth of SE5 cells pre-treated with anti-lipoteichoic acid $\left(0.49\right.$ net $\left.\log _{10} \quad \mathrm{cfu} / \mathrm{ml}\right)$ was significantly $(p<0.05)$ greater than the minimal growth $(0.16)$ of serum pre-treated cells (Fig. 2). Both these conditions induced greater viability of cells than the reduced net viability $(-0.66)$ of untreated cells $(p<0.0001)$.

\section{Lactoferrin binding following pre-incubation in anti-lipoteichoic acid}

SE5 cells bound iron-limited lactoferrin with a maximum relative adsorption of $12.5 \mu \mathrm{g} / \mathrm{ml}$ (Fig. 3). This bacterial strain also bound anti-lipoteichoic acid and,

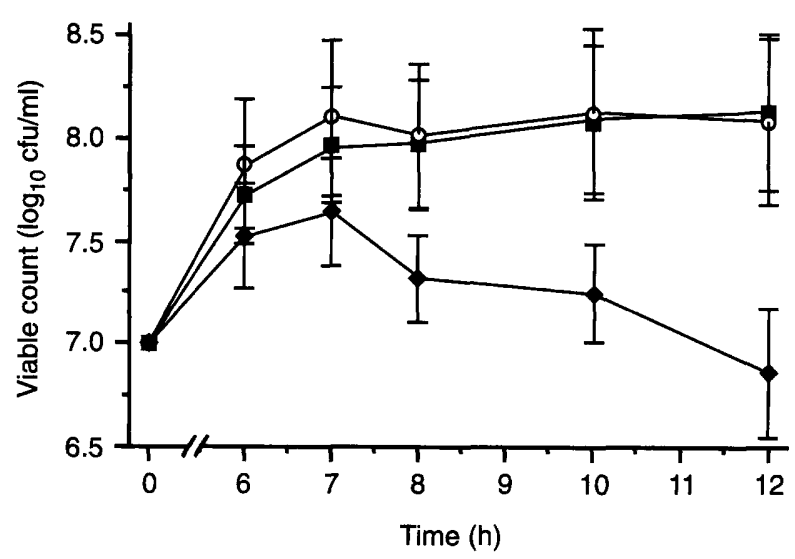

Fig. 1. Growth of SE5 cells in ATFS + LZ with lactoferrin added after $6 \mathrm{~h}(\boldsymbol{\square})$, in ATFS + holoLF with lysozyme added after $6 \mathrm{~h}(\mathrm{O})$ and ATFS $+\mathrm{LF}$ with lysozyme added after $6 \mathrm{~h}(\bullet)$. Results represent the mean of six experiments (bar, SD). 


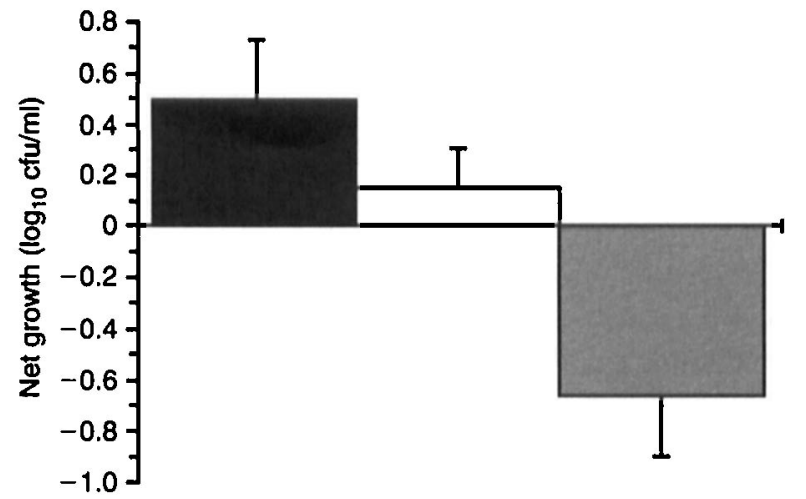

Fig. 2. Growth of SE5 cells, pre-treated with antilipoteichoic acid ( $\square$ ) serum ( $\square$ ) or with no pre-treatment (a) in ATFS + LF for $6 \mathrm{~h}$. Lysozyme was added and viability monitored for a further $6 \mathrm{~h}$. Results represent the mean of six experiments (bar, SD), expressed as the net growth $\left(\log _{10} \mathrm{cfu} / \mathrm{ml}\right)$ following addition of lysozyme.

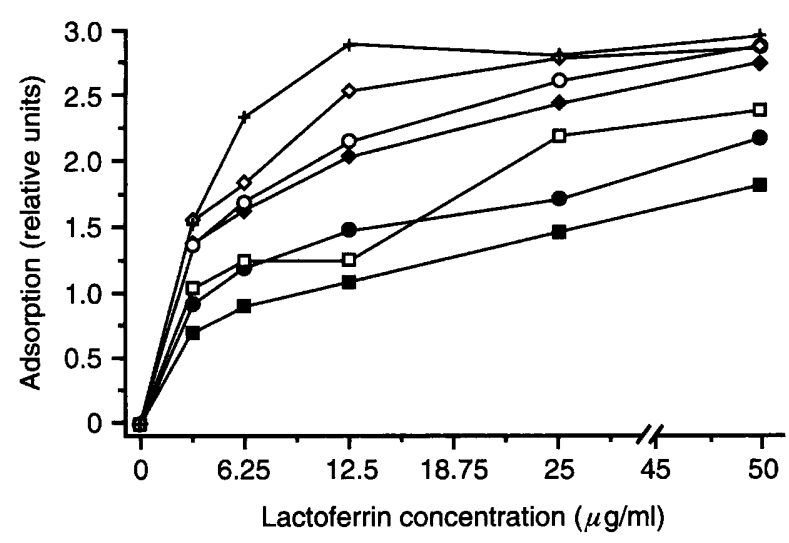

Fig. 3. Adsorption of lactoferrin to SE5 cells after no pre-treatment $(+)$ and pre-treatment with anti-lipoteichoic acid $(2 \%, 0.2 \% \bullet 0.02 \% \bullet)$ or rabbit serum $(2 \% \square, 0.2 \% \circ, 0.02 \% \diamond)$. Results represent the mean of four experiments expressed in relative units; SD $<42.2 \%$ of the mean.

with a reduced $(\mathrm{p}<0.01)$ relative adsorption, rabbit serum. After pre-treatment with various dilutions of anti-lipoteichoic acid or serum, there was a significant $(p<0.01)$ reduction only in the lactoferrin-binding of cells pre-treated with anti-lipoteichoic acid $2 \%$. No other statistically significant data were obtained. There was a general trend of increased lactoferrin binding with further dilution of anti-lipoteichoic acid, with the $0.02 \%$ concentration resulting in similar amounts of lactoferrin binding to those conditions with neither anti-lipoteichoic acid nor serum. Similarly, there was a general trend of reduced lactoferrin binding in the presence of serum $2 \%$, but with 0.2 and $0.02 \%$ similar amounts of lactoferrin were bound as in those conditions with neither anti-lipoteichoic acid nor serum. This correlates with the results shown in Fig. 4 of anti-lipoteichoic acid and serum binding of SE5 cells in which anti-lipoteichoic acid was bound $c$. 10 -fold more than serum.

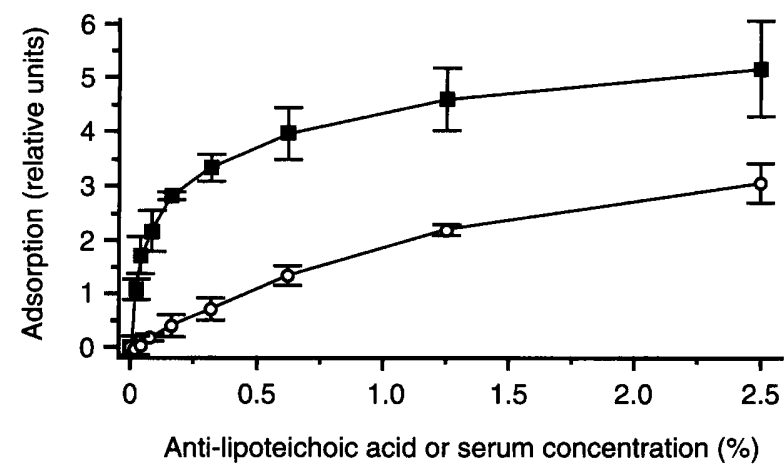

Fig. 4. Adsorption of anti-lipoteichoic acid (a) and serum (O) to SE5 cells. Results represent the mean of four experiments (bar, SD) expressed in relative units.

\section{Effect of lactoferrin on lipoteichoic acid release}

Lipoteichoic acid release was detected in both TSB and TSB containing lactoferrin (Table 1). The presence of lactoferrin led to an increased release (19.82) compared with the absence of lactoferrin (7.96), although this difference was not statistically significant.

\section{Effect of lactoferrin on autolytic activity}

The autolytic activity of $S$. epidermidis was measured by incubating cell-free supernates with suspensions of M. lysodeikticus. As shown in Fig. 5, the autolytic

Table 1. The release of lipoteichoic acid from the surface of SE5 cells incubated in TSB or TSB containing lactoferrin (TSB + LF)

\begin{tabular}{lc}
\hline Media & Mean (SD) LTA release \\
\hline TSB & $7.96(5.48)$ \\
TSB + LF & $19.82(9.54)$ \\
\hline
\end{tabular}

${ }^{*}$ Results represent the mean of four experiments expressed as the amount of lipoteichoic acid released in relative units.

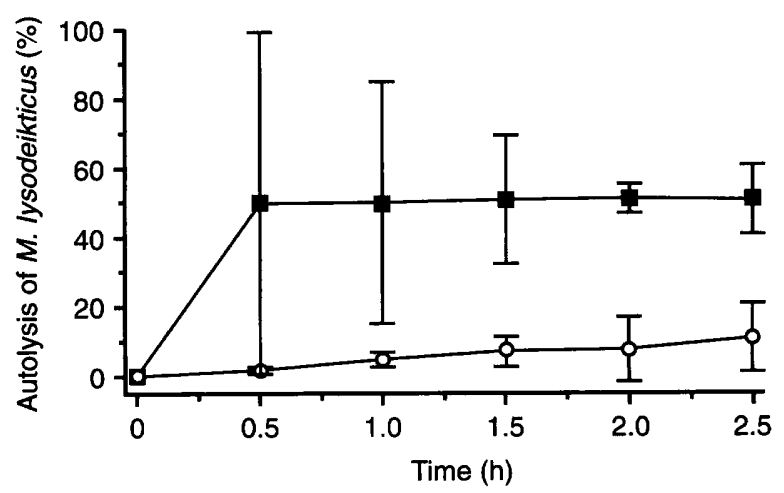

Fig. 5. Autolysis of $M$. lysodeikticus by the supernate of SE5 cells grown in TSB ( $\square$ ) or TSB containing lactoferrin (O). Results represent the mean of four experiments (bar, SD) expressed as the percentage autolysis of $M$. lysodeikticus, as measured spectrophotometrically at $570 \mathrm{~nm}$. 
activity of growing $S$. epidermidis cells was reduced in the presence of lactoferrin.

\section{Discussion}

Lactoferrin and lysozyme exert co-operative antimicrobial properties in vitro against $S$. epidermidis which are not apparent for these proteins individually [8]. In the present study, the mechanism of action of this cooperation was investigated. As lactoferrin increases the penetration of lysozyme into gram-negative bacteria [7], the effect of sequential supplementation of ATFS with lactoferrin and lysozyme on viability was assessed. Lactoferrin added to ATFS $6 \mathrm{~h}$ before lysozyme resulted in a bactericidal effect. Ironsaturated lactoferrin inhibited this antimicrobial action, as did the addition of lysozyme before lactoferrin. This suggests that lactoferrin increases the penetration of lysozyme in a similar fashion to that in gram-negative bacteria.

Sensitivity of $S$. aureus to lysozyme can be induced by the removal of lipoteichoic acid and it has been suggested that teichoic acid prevents the interaction between lysozyme and its peptidoglycan substrate $[13,14]$. Therefore, the present study investigated the interaction between lactoferrin and lipoteichoic acid. Occlusion of lipoteichoic acid binding sites with antilipoteichoic acid abolished the antimicrobial effect of lactoferrin and lysozyme, suggesting that the interaction of lactoferrin with lipoteichoic acid is important. The antibacterial synergy of lactoferrin and lysozyme against gram-negative bacteria probably occurs because of the disruption of outer-membrane permeability by lactoferrin [7]. Lactoferrin may have a similar mode of action on the lipoteichoic acid of gram-positive bacteria. Lactoferricin, a peptide generated from digestion of lactoferrin by pepsin, which probably represents the structural domain of lactoferrin responsible for its bactericidal properties [15], increases lysozyme-induced killing of $S$. epidermidis [16]. Optimal lactoferricin binding on to the cell surface of Bacillus subtilis occurs at $10^{6}$ molecules/bacteria, suggesting that it binds to highly repeated surface components such as teichoic acid [16].

Direct binding of cell-surface components is integral to the antimicrobial action of lactoferricin on $B$. subtilis [15] and of lactoferrin with lysozyme synergy on gramnegative bacteria [7]. Therefore, the effect of occlusion of lipoteichoic acid binding sites by anti-lipoteichoic acid on the adsorption of lactoferrin on to the surface of SE5 cells was investigated. Lactoferrin adsorption was reduced in a dose-dependent manner by anti-lipoteichoic acid. Lactoferrin binding to the LPS of gramnegative bacteria probably occurs through the direct interaction of the cationic surface subunit of lactoferrin with the anionic core of the LPS [7] and the physical presence of lactoferrin is thought to adversely affect normal membrane physiology, allowing greater penetration of lysozyme [7]. Other cationic proteins such as cathepsin G from neutrophils [17] and the lantibiotics Pep 5 and nisin bind to staphylococcal lipoteichoic acid as part of their antimicrobial mechanism [18].

The hydrophilic chain of $S$. epidermidis lipoteichoic acid is substituted with glucose and D-alanine [19]. Increasing the alanine ester substitution of lipoteichoic acid decreases the net negative charge and, as cationic autolysins bind to these negatively charged molecules, autolysin inhibition occurs concomitantly [20]. It is proposed that cationic autolysins in vivo are fixed to the negatively charged lipoteichoic acid via electrostatic interaction [21] similar to the electrostatic interactions which occur between cationic proteins and lipoteichoic acid [22]. In the present study, the autolytic activity of growing $S$. epidermidis cells was reduced in the presence of lactoferrin compared with that in its absence. This is contrary to previous findings that cationic polypeptides and the cationic peptide lantibiotics Pep5 and nisin displace and activate staphylococcal autolysins by association with lipoteichoic acid [18]. The reduction in autolysis induced by lactoferrin in the present study might occur by adsorption to lipoteichoic or teichoic acid sites such as the negatively charged phosphodiester groups and sterical hindrance of the release of autolysins.

Lactoferrin increased the amount of lipoteichoic acid released from the surface of SE5 cells compared with that released in media lacking lactoferrin. Leucocyte cationic proteins, heat treated and therefore acting as cationic proteins, also cause the release of lipoteichoic acid [23] and lactoferrin causes the release of LPS from the surface of gram-negative bacteria [7]. Lactoferrin-induced lipoteichoic acid release may expose more peptidoglycan residues to lysozyme, allowing lysis to occur.

In conclusion, this study has shown that lactoferrin increases the penetration of lysozyme into the cell matrix of $S$. epidermidis by binding to lipoteichoic acid. Lactoferrin also reduced autolysis and caused an increase in the release of lipoteichoic acid from the cell surface. It is proposed that lactoferrin and lysozyme exert a combined antimicrobial effect against $S$. epidermidis by the binding of lactoferrin to lipoteichoic acid, neutralising the negative charge of this structure and hence allowing greater access of lysozyme to the peptidoglycan.

Grant support was received from the Australian Federal Government through the Cooperative Research Centres Program and from Vistakon, a division of Johnson and Johnson Vision Research Inc.

\section{References}

1. Stryer L (ed) Mechanisms of enzyme action. In: Biochemistry, 3rd edn. New York, WH Freeman and Co. 1988: 201-211. 
2. Fleming $\mathrm{A}$. On a remarkable bacteriolytic element found in tissues and secretions. Proc $R$ Soc B 1922; 93: 306-317.

3. Selsted ME, Martinez RJ. Lysozyme: primary bactericidin in human plasma serum active against Bacillus subtilis. Infect Immun 1978; 20: 782-791.

4. Arnold RR, Brewer M, Gauthier JJ. Bactericidal activity of human lactoferrin: sensitivity of a variety of microorganisms. Infect Immun 1980; 28: 893-898.

5. Arnold RR, Russell JE, Champion WJ, Brewer M, Gauthier JJ. Bactericidal activity of human lactoferrin: differentiation from the stasis of iron deprivation. Infect Immun 1982; 35: 792-799.

6. Ellison RT, Giehl TJ, LaForce FM. Damage of the outer membrane of enteric Gram-negative bacteria by lactoferrin and transferrin. Infect Immun 1988; 56: 2774-2781.

7. Ellison RT, Giehl TJ. Killing of Gram-negative bacteria by lactoferrin and lysozyme. J Clin Invest 1991; 88: 1080-1091.

8. Leitch EC, Willcox MDP. Synergic antistaphylococcal properties of lactoferrin and lysozyme. J Med Microbiol 1998; 47: $837-842$

9. Naidu AS, Arnold RR. Lactoferrin interaction with Salmonellae potentiates antibiotic susceptibility in vitro. Diagn Microbiol Infect Dis 1994; 20: 69-75.

10. Leitch EC, Willcox MDP. Lactoferrin increases the susceptibility of $S$. epidermidis biofilms to lysozyme and vancomycin. Curr Eye Res 1998; 18 (in press).

11. Leitch EC, Willcox MDP. Interactions between the constitutive host defences of tears and Staphylococcus epidermidis. Aust NZ J Ophthalmol 1997; 25 Suppl 1: 20-22.

12. Fischer W, Rosel P, Koch HU. Effect of alanine ester substitution and other structural features of lipoteichoic acids on their inhibitory activity against autolysins of Staphylococcus aureus. J Bacteriol 1981; 146: 467-475.

13. Morse SI. Biological attributes of staphylococcal cell walls. Ann NY Acad Sci 1965; 128: 191-213.

14. Johansen $C$. Enzyme and cationic peptides with antibacterial activity. $\mathrm{PhD}$ thesis. 1997

15. Bellamy WR, Wakabayashi $H$, Takase $M$, Kawase $K$, Shimamura S, Tomita M. Role of cell-binding in the antibacterial mechanism of lactoferricin B. J Appl Bacteriol 1993; 75: 478-484.

16. Bellamy W, Takase $M$, Yamauchi $K$, Wakabayashi H, Kawase $\mathrm{K}$, Tomita $\mathrm{M}$. Identification of the bactericidal domain of lactoferrin. Biochim Biophys Acta 1992; 1121: 130-136.

17. Shafer WM, Onunka VC. Mechanism of staphylococcal resistance to non-oxidative antimicrobial action of neutrophils: importance of $\mathrm{pH}$ and ionic strength in determining the bactericidal action of Cathepsin G. J Gen Microbiol 1989; 135 : $825-830$.

18. Bierbaum G, Sahl H-G. Influence of cationic peptides on the activity of the autolytic endo- $\beta$ - $N$-acetylglucosaminidase of Staphylococcus simulans 22. FEMS Microbiol Lett 1988; 58: 223-228.

19. Ruhland GJ, Fiedler F. Occurrence and structure of lipoteichoic acids in the genus Staphylococcus. Arch Microbiol 1990; 154: 375-379.

20. Fischer W. Lipoteichoic acid and lipids in the membrane of Staphylococcus aureus. Med Microbiol Immunol 1994; 183: $61-76$.

21. Wecke J, Perego M, Fischer W. D-alanine deprivation of Bacillus subtilis teichoic acids is without effect on cell growth and morphology but affects the autolytic activity. Microb Drug Resist 1996; 2: 123-129.

22. Ofek I, Simpson WA, Beachey EH. Formation of molecular complexes between a structurally defined $M$ protein and acylated or deacylated lipoteichoic acid of Streptococcus pyogenes. J Bacteriol 1982; 149: 426-433.

23. Sela MN, Lahav M, Ginsburg I. Effect of leukocyte hydrolases on bacteria. IX. The release of lipoteichoic acid from Group A streptococci and from Strep. mutans by leukocyte extracts and by lysozyme: relation to tissue damage in inflammatory sites. Inflammation 1977; 2: 151-164. 